\title{
On the photophysical and electrochemical studies of dye-sensitized solar cells with the new dye CYC-B1
}

\author{
Jian-Ging Chen ${ }^{\mathrm{a}}$, Chia-Yuan Chen ${ }^{\mathrm{b}}$, Shi-Jhang $\mathrm{Wu}^{\mathrm{b}}$, Jheng-Ying $\mathrm{Li}^{\mathrm{b}}$, \\ Chun-Guey $\mathrm{Wu}^{\mathrm{b}, * *}$, Kuo-Chuan Ho ${ }^{\mathrm{a}, \mathrm{c}, *}$ \\ a Department of Chemical Engineering, National Taiwan University, Taipei 10617, Taiwan \\ ${ }^{\mathrm{b}}$ Department of Chemistry, National Central University, Chung-Li 32054, Taiwan \\ c Institute of Polymer Science and Engineering, National Taiwan University, Taipei 10617, Taiwan
}

\section{A R T I C L E I N F O}

\section{Article history:}

Received 20 December 2007

Received in revised form 6 July 2008

Accepted 7 August 2008

Available online 19 September 2008

\section{Keywords:}

Dye-sensitized solar cells

Nanocrystallined $\mathrm{TiO}_{2}$

Ruthenium photosensitizer

\begin{abstract}
A B S T R A C T
In this study, the photoelectrochemical characteristics of a ruthenium photosensitizer with an alkyl bithiophene group, designated as CYC-B1, are studied. The effect of mesoporous $\mathrm{TiO}_{2}$ film thickness on the photovoltaic performance of CYC-B1 and N3 dye-sensitized solar cells was investigated. The performance of the dye-sensitized nanocrystalline $\mathrm{TiO}_{2}$ solar cells (DSSC) fabricated using CYC-B1 dye-anchored $\mathrm{TiO}_{2}$ photoelectrode showed a convincing enhancement in cell efficiency when the $\mathrm{TiO}_{2}$ film thickness was increased from $3 \mu \mathrm{m}$ (eff. $=5.41 \%$ ) to $6 \mu \mathrm{m}$ (eff. $=7.19 \%$ ). The efficiency of the CYC-B1-sensitized DSSC was maximum at $6 \mu \mathrm{m}$ of the $\mathrm{TiO}_{2}$ film thickness, reached its limiting value and remained constant up to $53 \mu \mathrm{m}$, although a similar trend was also observed for N3 dye-sensitized DSSC, however, the maximum efficiency achieved was only at $27 \mu \mathrm{m}$ thickness (eff. $=6.75 \%$ ). As expected, the photocurrent density generated in the DSSC modified by CYC-B1 dye is larger than that from N3 dye. The effect of guanidinium thiocyanate (GuSCN) (additive) addition to the electrolyte on the photovoltaic performance of DSSCs based on CYC-B1 was also investigated. Furthermore, the electrochemical impedance spectroscopy (EIS) technique and photo-transient laser method have been employed to analyze the charge transfer resistances $\left(R_{\mathrm{ct}}\right)$ and the lifetime of the injected electrons on the $\mathrm{TiO}_{2}$ containing different thicknesses.
\end{abstract}

(c) 2008 Elsevier B.V. All rights reserved.

\section{Introduction}

Dye-sensitized nanocrystalline $\mathrm{TiO}_{2}$ solar cells (DSSCs), which possess high conversion of sunlight to electricity, by means of harvesting of solar irradiation by the sensitizer, have attracted considerable attention in scientific research and practical applications [1,2]. In these DSSCs, sensitizing dye molecules must be chemically adsorbed on the porous nanocrystalline $\mathrm{TiO}_{2}$ surfaces, and they harvest solar light ranging from the UV-visible and near-IR regions just like photovoltaic semiconductor diode interfaces.

However, the conversion efficiency of the DSSCs is much lower than that of the silicon-based photovoltaic cells. To obtain a high conversion efficiency, optimization of the short-circuit photocurrent $\left(J_{\mathrm{sc}}\right)$ and open-circuit potential $\left(V_{\mathrm{oc}}\right)$ of the cell is essential.

\footnotetext{
** Also corresponding author. Tel.: + 88634227151 x65903; fax: +88634227664

* Corresponding author at: Department of Chemical Engineering, National Taiwan University, Taipei 10617, Taiwan. Tel.: +88622366 0739; fax: +886223623040

E-mail addresses: t610002@cc.ncu.edu.tw (C.-G. Wu), kcho@ntu.edu.tw (K.-C. Ho).
}

Up to till date, a highest conversion efficiency of $11 \%$ was achieved by using cis-di(thiocyanato) bis(2,2'-bipyridyl-4,4'-dicarboxylate)ruthenium(II) (N3) as a photosensitizer [3,4]. Further, in order to improve the photovoltaic performance and stability of the DSSCs, extensive efforts have been focused on the synthesis of new sensitizer possessing high efficiency and the search for stable electrolytes and/or new photoanode materials [5-8].

In recent years, the most investigated efficient sensitizers are ruthenium complexes, such as N719 [9], Z907 [10], k77 [11], HRS1 [12] dyes, which possess effective charge separation at the MLCT (metal-to-ligand charge transfer) absorption band in the visible solar light region. Enhancement of thermal and long-term stability was accomplished, for instance with the $Z 907$ dye, by anchoring a long, hydrophobic alkyl group on the ruthenium dye molecules [10]. On the other hand, several organic dye sensitizers have been reported for the DSSCs, having considerable incident photon to current efficiency (IPCE) partly due to the high molar extinction coefficient of the conjugated $\pi$-bonds coupled with the aromatic ring [6]. In addition, the effect of additives in the electrolyte also has been considered. For example, guanidinium thiocyanate (GuSCN) has been used as an additive in organic electrolytes [13,14], as it remarkably improves the photovoltage of 
DSSCs due to a reduction in dark current, and thus improves the conversion efficiency [4,13].

A new ruthenium photosensitizer CYC-B1 was recently reported by our group [15], in which one of the dcbpy ligands (4,4'-dicarboxylic acid-2,2'-bipyridine) in N3 was replaced with abtpy (4,4'-di-2-octyl-5-(thiophen-2-yl)thiophen-2-yl-2,2'-bipyridine), a bipyridine ligand substituted with alkyl bithiophene groups. In evidence, CYC-B1 has the highest absorption coefficient among the Ru-based photosensitizers used earlier in DSSCs, and its power-conversion efficiency is $10 \%$ higher than that of $\mathrm{N} 3$ under identical cell fabrication and measuring procedures [15].

In this work, we would like to explore the influences of experimental conditions, such as the effect of different thicknesses of $\mathrm{TiO}_{2}$ layer and the effect of GuSCN added as an additive, on the photovoltaic performance of the DSSC sensitized with CYC-B1. Moreover, the electrochemical impedance spectroscopy (EIS) technique and photo-transient laser method have been employed to analyze the resistances of the various cells and measure the lifetime of the injected electrons, respectively.

\section{Experimental section}

\subsection{Materials}

Anhydrous LiI, $\mathrm{I}_{2}$, poly(ethylene glycol) (PEG), titanium (IV) isopropoxide (TTIP) (+98\%) and 4-tert-butylpyridine (TBP) were obtained from Merck. Acetonitrile was purchased from Merck and dehydrated by the addition of molecular sieves ( $4 \AA$ ) into it. Furthermore, CYC-B1 photosensitizer was prepared in a typical one-pot synthesis, reported in the previous work [15].

\subsection{Preparation of $\mathrm{TiO}_{2}$ thin films and the cell assembly}

The preparation of $\mathrm{TiO}_{2}$ precursor and the electrode fabrication were carried out based on previous reports [16] except after autoclave treatment, where the solution was concentrated to 13 wt\% and PEG (MW 20,000) was added to the $\mathrm{TiO}_{2}$ paste to prevent the film from cracking during drying. The $\mathrm{TiO}_{2}$ paste was coated on a fluorine-doped tin oxide (FTO) glass plate using glass rod. For the first coating, the $\mathrm{TiO}_{2}$ paste incorporated with PEG (MW 20,000) was used. A second coating was made with the same paste followed by a final coating, which contains mixture of light scattering particles of $\mathrm{TiO}_{2}$ (300 (30) and $20 \mathrm{~nm}$ (70 wt\%)) for reducing the light loss by back scattering. An active surface area of $0.16 \mathrm{~cm}^{2}$ of electrode was fixed and immersed overnight in an acetonitrile: TBP solution in the volume ratio of $1: 1$ that containing $2 \times 10^{-4} \mathrm{M}$ dye (either CYC-B1 or N3).

A platinum-sputtered FTO $(8 \Omega / \mathrm{sq})$ conducting glass plate (Pt thickness of $100 \mathrm{~nm}$ ) was used as the counter-electrode and the electrolyte was composed of $0.5 \mathrm{M} \mathrm{Lil} / 0.05 \mathrm{M} \mathrm{I}_{2} / 0.5 \mathrm{M}$ TBP in acetonitrile. In addition, GuSCN was added to the electrolyte if necessary. The electrolyte solution was sprayed on both the dyeimmobilized photoanode and Pt-sputtered FTO glass and then, they were sandwiched together using cell holders immediately.

\subsection{Instrumentation}

The cell was illuminated by an Oriel solar simulator (\#6266) equipped with a water-based IR filter under AM 1.5 filter (Oriel, \#81075) irradiation. The photoelectrochemical characteristics of the DSSCs were recorded with a potentiostat/galvanostat (PGSTAT 30, Autolab, Eco-Chemie, Netherland). EIS were obtained by the above-mentioned potentiostat/galvanostat equipped with FRA2 module under constant light illumination of $100 \mathrm{~mW} / \mathrm{cm}^{2}$ at the open-circuit voltage. The frequency range explored and ac amplitude was set at $10 \mathrm{mHz}$ to $65 \mathrm{kHz}$ and at $10 \mathrm{mV}$, respectively, between the counter-electrode and the working electrode. The impedance spectra were analyzed by an equivalent circuit model interpreting the characteristics of the DSSCs [17]. The photovoltage transients of assembled devices were recorded with a digital oscilloscope (LeCroy, model LT322). Pulsed laser excitation was applied by a frequency-doubled Q-switched Nd:YAG laser (Spectra-Physics laser, model Quanta-Ray GCR-3-10) with $2 \mathrm{~Hz}$ repetition rate at $532 \mathrm{~nm}$ and $7 \mathrm{~ns}$ pulse width at half-height. The beam size was slightly larger than $0.16 \mathrm{~cm}^{2}$ to cover the area of the device with incident energy of $1 \mathrm{~mJ} / \mathrm{cm}^{2}$. The average electron lifetime was estimated approximately by fitting a decay of the open-circuit voltage transient with $\exp \left(-t / \tau_{\mathrm{e}}\right)$, where $t$ is time and $\tau_{\mathrm{e}}$ is an average time constant before recombination [18].

\section{Results and discussions}

\subsection{The effect of the $\mathrm{TiO}_{2}$ film thickness}

The thickness of the $\mathrm{TiO}_{2}$ film is one of the important factors and shows a dominant effect on the performance of the DSSC. The influence of the thickness of the $\mathrm{TiO}_{2}$ film on both CYC-B1- and N3-sensitized DSSCs is shown in Fig. 1. The efficiency of the DSSC fabricated with CYC-B1 dye- $\mathrm{TiO}_{2}$ photo-electrode showed a drastic enhancement in cell efficiency as the $\mathrm{TiO}_{2}$ film thickness was increased from 3 (eff. $=5.41 \%$ ) to $6 \mu \mathrm{m}$ (eff. $=7.19 \%$ ). However, as seen in Fig. 1, the cell efficiency remained almost constant on further increase of the $\mathrm{TiO}_{2}$ film thickness up to $53 \mu \mathrm{m}$. Similarly, the maximum cell efficiency for N3 dye $(6.75 \%)$ was reached while the thickness of the $\mathrm{TiO}_{2}$ film was maintained at $27 \mu \mathrm{m}$. Under certain film thickness, it is generally observed that thicker film adsorbs more dye molecules and thus, leading to the enhancement in the photocurrent of the DSSC. The photocurrent densities of DSSCs made with CYC-B1 dye absorbed on different thicknesses of the $\mathrm{TiO}_{2}$ film are higher than those of DSSCs made with N3 dye (inset in Fig. 1). The drastic increase in photocurrent density, observed with CYC-B1 when the $\mathrm{TiO}_{2}$ thickness was increased from 3 to $6 \mu \mathrm{m}$, can be ascribed to the superior light-harvesting capacity of CYC-B1 dye. Nevertheless, the increase of $\mathrm{TiO}_{2}$ film thickness resulting in the decrease of $V_{\mathrm{oc}}$ was observed. Additionally, in the case of CYC-B1 dye, the fill factor, which is not shown in Fig. 1, decreases from 0.67 to 0.59 as

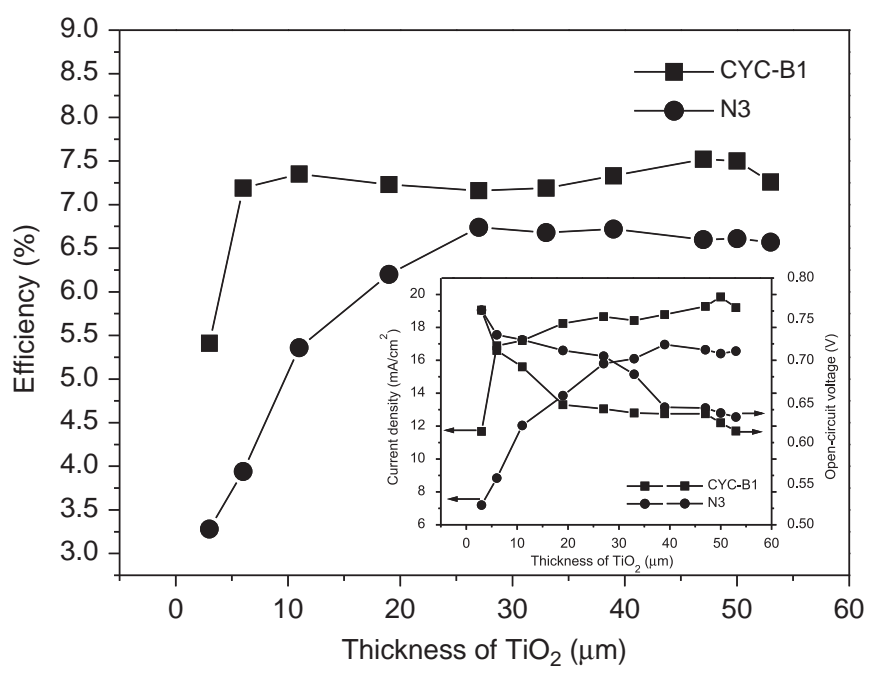

Fig. 1. Photovoltaic performance of solar cells made with CYC-B1 dye and N3 dye based on different $\mathrm{TiO}_{2}$ thicknesses. Insets: current density as well as $V_{\text {oc }} \mathrm{Vs} \mathrm{TiO}_{2}$ thickness collected at a constant illumination of $100 \mathrm{~mW} / \mathrm{cm}^{2}$. 
the $\mathrm{TiO}_{2}$ film thickness is increased from 6 to $53 \mu \mathrm{m}$. This is apparently due to the increase in series resistance.

This interesting behavior may be explained by the following two factors. The first factor has to do with the average pore diameter of the $\mathrm{TiO}_{2}$ film $(11.5 \mathrm{~nm})$ obtained at the hydrothermal temperature of $240^{\circ} \mathrm{C}$ [16]. It has been known that $\mathrm{N} 3$ dye molecules could occupy a space of $3.3 \mathrm{~nm}$ (1.65 nm radius [19]) and the radius of triiodide ion in $\mathrm{CH}_{3} \mathrm{CN}$ is about $4 \mathrm{~nm}$ [20]. Hence, the residual space of $\mathrm{TiO}_{2}$ is spared only for the diffusion of the redox couple. Under this condition, if the $\mathrm{TiO}_{2}$ film is thicker than a particular value, it will be very difficult for the redox mediators to diffuse into the $\mathrm{TiO}_{2}$ matrix. Besides, the electron transport in the electrolyte-filled $\mathrm{TiO}_{2}$ mesoporous film is coupled to the ionic motion due to ambipolar diffusion [21,22]. As a result of this, only a finite amount of dye molecules was reduced by mediator ions, limiting the continuous increasing in the current. The second factor has to do with the lifetime of electrons. It is generally accepted that the average electron lifetime can be estimated by fitting a decay of the open-circuit voltage transient with $\exp \left(-t / \tau_{\mathrm{e}}\right)$, where $t$ is the time and $\tau_{\mathrm{e}}$ is an average time constant before recombination. For comparison, the effect of molar ratio on the average electron lifetime was studied by the laser induced photovoltage transient technique. Electron diffusion coefficient was estimated by fitting a decay of the current transient with $\exp \left(-t / \tau_{C}\right)$, which was derived from the equation of continuity for electrons in the conduction band [23], where $t$ is time and $\tau_{\mathrm{C}}$ is an average collection time constant. Finally, the apparent diffusion coefficient of electrons $\left(D_{\mathrm{e}}\right)$ can be estimated by using

$D_{\mathrm{e}}=\frac{w^{2}}{2.35 \tau_{\mathrm{C}}}$

where $w$ is the film thickness and the factor 2.35 arises from the geometry of the diffusion problem [24].

From the photovoltage transients of the assembled DSSCs, the average lifetime of photo-injected electrons of the $\mathrm{TiO}_{2}$ film incorporated with CYC-B1 dye $(4.70 \mathrm{~ms})$ is larger than that of the $\mathrm{TiO}_{2}$ film incorporated with $\mathrm{N} 3$ dye $(3.96 \mathrm{~ms})$, as shown in Fig. 2. The photovoltage transient is shown in the inset of Fig. 2 with $Y$ axis plotted in a logarithmic scale. It can be seen that a near-linear fitting has been satisfied, thus the average electron lifetime can be obtained from the slope. Besides, from the inserted table in Fig. 2, the electron diffusion length and the electron diffusion coefficient of DSSCs made with CYC-B1 and N3 are $17 \mu \mathrm{m}$ and $2.2 \times 10^{-4}$

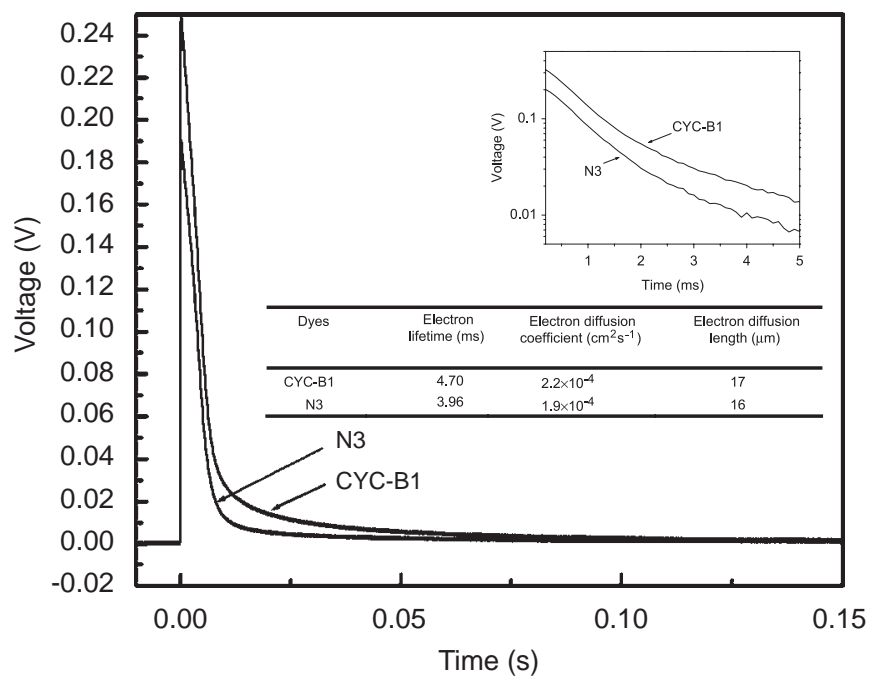

Fig. 2. Photovoltage transients induced by pulse UV radiation for the CYC-B1 and N3 dye-sensitized $\mathrm{TiO}_{2}$ electrodes. $\mathrm{cm}^{2} \mathrm{~s}^{-1}$ as well as $16 \mu \mathrm{m}$ and $1.9 \times 10^{-4} \mathrm{~cm}^{2} \mathrm{~s}^{-1}$, respectively. Consequently, the photocurrent density generated by CYC-B1 dye is larger than that by N3 dye at the similar film thickness. Therefore, the drastic increase in cell efficiency observed with CYC-B1 dye can be ascribed to its superior light-harvesting capacity.

\subsection{EIS analysis}

The EIS technique was used to characterize the kinetics of the DSSCs by analyzing the variation in impedances associated with the different configurations of cells [25]. In this work, the analysis was mainly done using Nyquist plots (Fig. 3a and b) associated with the different $\mathrm{TiO}_{2}$ film thicknesses sensitized with CYC-B1 or $\mathrm{N} 3$, respectively, measured at open-circuit voltage. The ohmic serial resistance $\left(R_{\mathrm{s}}\right)$ corresponds to the electrolyte and the FTO resistance and the resistances $R_{\text {ct2 }}$ relate to charge-transfer resistance occurring at the dye-sensitized $\mathrm{TiO}_{2}$ film/solution interface [26]. The results obtained from Fig. 4 show the lower

a

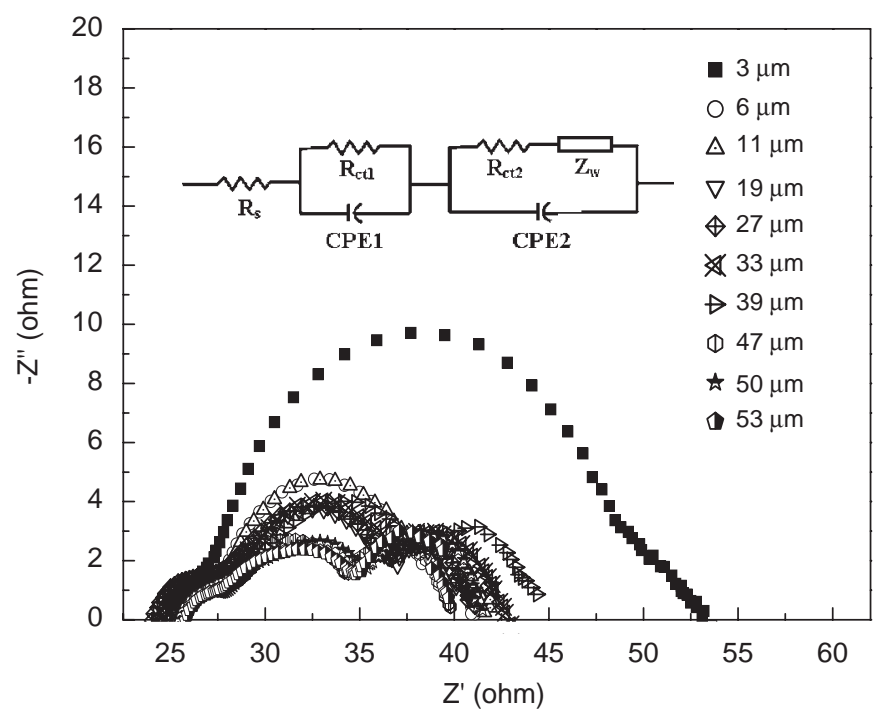

b

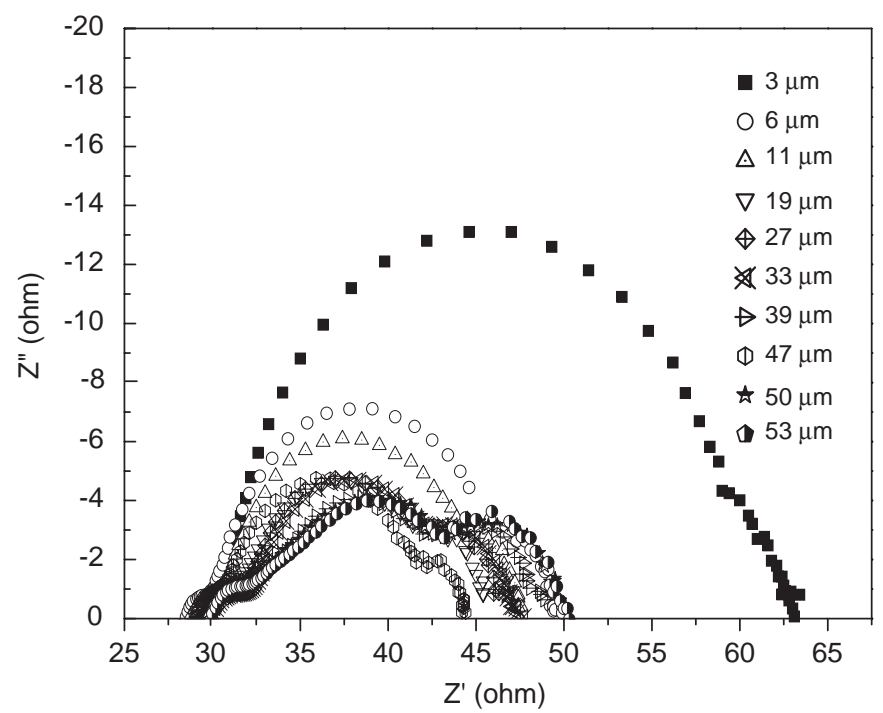

Fig. 3. Nyquist plots of the DSSCs fabricated with the different $\mathrm{TiO}_{2}$ thicknesses as working electrodes incorporated with (a) CYC-B1 or (b) N3 dyes at a constant illumination of $100 \mathrm{~mW} / \mathrm{cm}^{2}$. 


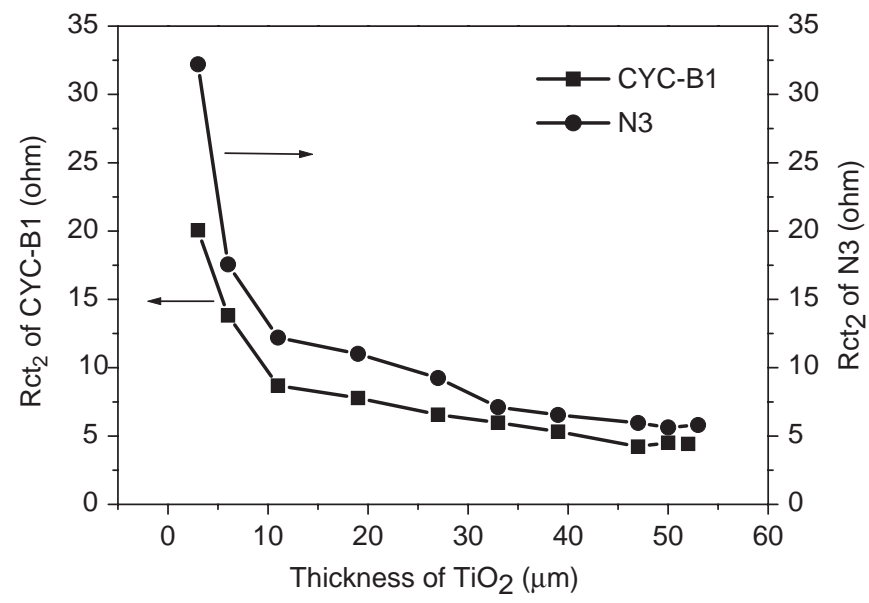

Fig. 4. Plot of charge resistance, $R_{\mathrm{ct} 2}$, obtained from the fitting of EIS results (in Fig. 3) vs. different $\mathrm{TiO}_{2}$ thicknesses as working electrodes incorporated with CYC-B1 or N3 dye.

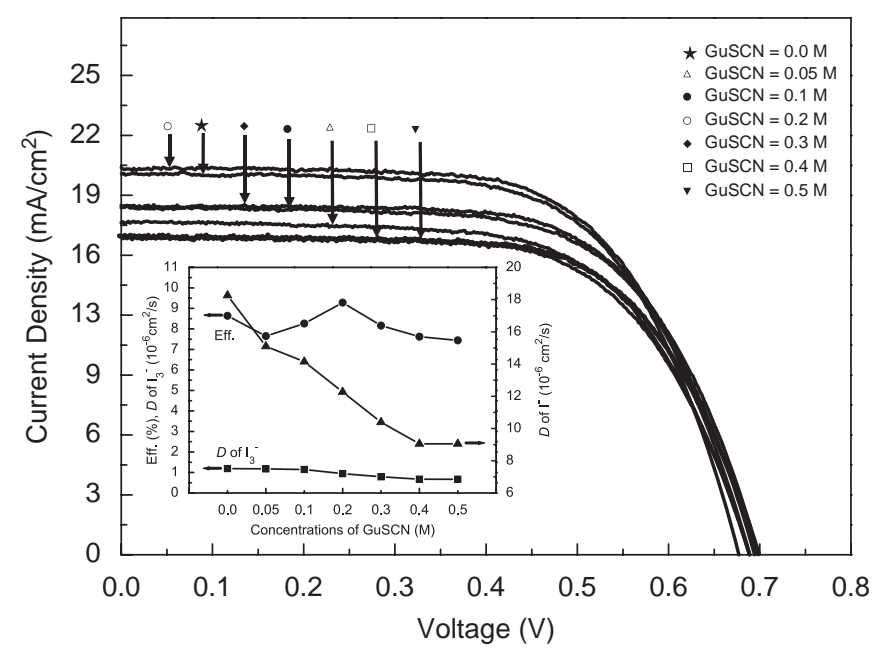

Fig. 5. The $I-V$ curves of the DSSCs made with CYC-B1 dye incorporated with various concentrations of GuSCN in the electrolyte. Insets: efficiencies of the DSSC and diffusion coefficients vs. various concentrations of GuSCN.

electron transfer resistance $\left(R_{\mathrm{ct} 2}\right)$ for CYC-B1 dye-sensitized DSSC than that of $\mathrm{N} 3$ dyes-sensitized DSSC under the different $\mathrm{TiO}_{2}$ thicknesses. In addition, the higher photocurrent for CYC-B1 dye-sensitized DSSC due to CYC-B1 dye possesses higher metal-to-ligand charge transfer (MLCT) transitions than that of N3 was demonstrated [15], leading to lower electron transfer resistance $\left(R_{\mathrm{ct} 2}\right)$.

\subsection{Concentration of GuSCN as an additive}

The effect of GuSCN as additive on the photovoltaic performance of the DSSC was first reported by Grätzel et al. [13]. They concluded that coadsorption of GuSCN with dyes such as N 719 and N3 improved the $V_{\text {oc }}$ of the DSSC obviously due to the reduction of dark current [13]. In this study, we have also investigated the effect of addition of GuSCN in the electrolyte, which consisted of $0.5 \mathrm{M}$ LiI, $0.5 \mathrm{M}$ TBP and $0.05 \mathrm{M} \mathrm{I}_{2}$. This effect was further confirmed from $I-V$ curves obtained from the solar cells containing GuSCN under illumination of $100 \mathrm{~mW} / \mathrm{cm}^{2}$ and the results are shown in Fig. 5. In addition, from the inset (in Fig. 5), the $D$ values (diffusion coefficient) of $I^{-}$decreased with the increase of the amount of GuSCN; nevertheless, $D$ values of $I_{3}^{-}$ were unaffected by the increase of the amount of GuSCN, which is explained in terms of a Grotthuss-type transport mechanism [27-29]. Addition of GuSCN prevents the oxidation of $I^{-}$by providing a more effective insulating barrier layer and results in the decrease of photocurrent of the DSSCs in particular at the $0.2 \mathrm{M}$ of GuSCN. On the other hand, at $0.2 \mathrm{M}$ of GuSCN, adsorption of GuSCN not only reduces the electron recombination between the $\mathrm{TiO}_{2}$ surface and $I_{3}^{-}$, but also shifts the band edge to negative potential, as reported in Grätzel's work [13].

Consequently, the optimum concentration of the GuSCN is considered as $0.2 \mathrm{M}$ in the CYC-B1 dye-sensitized solar cells. Addition of $0.2 \mathrm{M}$ of GuSCN showed a bit increase in both $J_{\mathrm{sc}}$ $\left(20.45 \mathrm{~mA} / \mathrm{cm}^{2}\right)$ and $V_{\text {oc }}(0.690 \mathrm{~V})$ for the cell containing CYC-B1 dye systems when compared to the absence of GuSCN (Jsc $\left.19.97 \mathrm{~mA} / \mathrm{cm}^{2} ; V_{\text {oc }}: 0.675 \mathrm{~V}\right)$. In this case, we did not perform the study for the cell efficiency vs. GuSCN concentration at various $\mathrm{TiO}_{2}$ film thicknesses. It is noticed that the addition of $0.2 \mathrm{M}$ of GuSCN in electrolyte increased $V_{\text {oc }}$ and $J_{\text {sc }}$ of the solar cell. The maximum efficiency achieved is $9.58 \%$.

\section{Conclusion}

The effect of thickness of mesoporous $\mathrm{TiO}_{2}$ film on the performance of the DSSCs was investigated for both CYC-B1 and N3 dyes. The efficiency of the DSSC made with CYC-B1 dye showed an appreciable enhancement in cell efficiency as the $\mathrm{TiO}_{2}$ film thickness was increased from 3 (eff. $=5.41 \%$ ) to $6 \mu \mathrm{m}$ (eff. $=7.19 \%$ ) and remained constant on further increase of the $\mathrm{TiO}_{2}$ film thickness up to $53 \mu \mathrm{m}$. As for N3 dye, the cell efficiency reached a maximum value while the thickness of $\mathrm{TiO}_{2}$ film was maintained at $27 \mu \mathrm{m}$ (eff. $=6.75 \%$ ). As expected, the photocurrent density generated by the CYC-B1 dye is larger than that of the N3 dye. Upon addition of $0.2 \mathrm{M} \mathrm{GuSCN}$, the efficiency of the cell sensitized with the new dye CYC-B1 improved to $9.58 \%$.

\section{Acknowledgements}

This work was financially supported by the National Research Council of Taiwan, the Republic of China. This work was also partially supported by the Academia Sinica, Taipei, Taiwan, the Republic of China.

\section{References}

[1] B. O'Regan, M. Grätzel, A low-cost, high-efficiency solar cell based on dyesensitized colloidal $\mathrm{TiO}_{2}$ films, Nature 353 (1991) 737-739.

[2] M.K. Nazeeruddin, A. Kay, I. Rodicio, R.H. Baker, E. Muller, P. Liska N. Vlachopoulos, M. Grätzel, Conversion of light to electricity by cis-X2bis (2,2'-bipyridyl-4,4'-dicarboxylate)ruthenium(II) charge-transfer sensitizers $\left(X=\mathrm{Cl}_{-}, \mathrm{Br}-, \mathrm{I}-, \mathrm{CN}-\right.$, and $\left.\mathrm{SCN}-\right)$ on nanocrystalline titanium dioxide electrodes, J. Am. Chem. Soc. 115 (1993) 6382-6390.

[3] Q. Wang, S. Ito, M. Grätzel, F.F. Santiago, I.M. Seró, J. Bisquert, T. Bessho, H. Imai, Characteristics of high efficiency dye-sensitized solar cells, J. Phys. Chem. B 110 (2006) 25210-25221.

[4] J.M. Kroon, N.J. Bakker, H.J.P. Smit, P. Liska, K.R. Thampi, P. Wang, S.M. Zakeeruddin, M. Grätzel, A. Hinsch, S. Hore, U. Würfel, R. Sastrawan, J.R. Durrant, E. Palomares, H. Pettersson, T. Gruszecki, J. Walter, K. Skupien, G.E. Tulloch, Nanocrystalline dye-sensitized solar cells having maximum performance, Prog. Photovolt: Res. Appl. 15 (2007) 1-18.

[5] K. Hara, M. Kurashige, Y. Kan-oh, C. Kasada, A. Shinpo, S. Suga, K. Sayama, H. Arakawa, Design of new coumarin dyes having thiophene moieties for highly efficient organic-dye-sensitized solar cells, New J. Chem. 27 (2003) 783-785.

[6] T. Horiuchi, H. Miura, K. Sumioka, S. Uchida, High efficiency of dye-sensitized solar cells based on metal-free indoline dyes, J. Am. Chem. Soc. 126 (2004) 12218-12219.

[7] M. Adachi, Y. Murata, J. Takao, J. Jiu, M. Sakamoto, F. Wang, Highly efficient dye-sensitized solar cells with a titania thin-film electrode composed 
of a network structure of single-crystal-like $\mathrm{TiO}_{2}$ nanowires made by the "oriented attachment" mechanism, J. Am. Chem. Soc. 126 (2004) 14943-14949.

[8] M. Zukalova, A. Zukal, L. Kavan, M.K. Nazeeruddin, P. Lisa, M. Grätzel, Organized mesoporous $\mathrm{TiO}_{2}$ films exhibiting greatly enhanced performance in dye-sensitized solar cells, Nano Lett. 5 (2005) 1789-1792.

[9] M.K. Nazeeruddin, F.D. Angelis, S. Fantacci, A. SElloni, G. Viscardi, P. Liska S. Ito, B. Takeru, M. Grätzel, Combined experimental and DFT-TDDFT computational study of photoelectrochemical cell ruthenium sensitizers, J. Am. Chem. Soc. 127 (2005) 16835-16847.

[10] P. Wang, S.M. Zakeeruddin, J.E. Moser, M.K. Nazeeruddin, T. Sekiguchi, M. Grätzel, A stable quasi-solid-state dye-sensitized solar cell with an amphiphilic ruthenium sensitizer and polymer gel electrolyte, Nat. Mater. 2 (2003) 402-407.

[11] D. Kuang, C. Klein, S. Ito, J.E. Moser, R.H. Baker, N. Evants, F. Duriaux, C. Grätzel, S.M. Zakeeruddin, M. Grätzel, High-efficiency and stable mesoscopic dyesensitized solar cells based on a high molar extinction coefficient ruthenium sensitizer and nonvolatile electrolyte, Adv. Mater. 19 (2007) 1133-1137.

[12] K.J. Jiang, N. Masaki, J.B. Xia, S. Noda, S. Yanagida, A novel ruthenium sensitizer with a hydrophobic 2-thiophen-2-yl-vinyl-conjugated bipyridy ligand for effective dye sensitized $\mathrm{TiO}_{2}$ solar cells, Chem. Commun. (2006) 2460-2462.

[13] M. Grätzel, Conversion of sunlight to electric power by nanocrystalline dyesensitized solar cells, J. Photochem. Photobiol. A: Chem. 164 (2004) 3-14.

[14] Z.S. Wang, K. Hara, Y. Dan-oh, C. Kasada, A. Shinpo, S. Suga, H. Arakawa, H. Sugihara, Photophysical and (photo)electrochemical properties of a coumarin dye, J. Phys. Chem. B 109 (2005) 3907-3914.

[15] C.Y. Chen, S.J. Wu, C.G. Wu, J.G. Chen, K.C. Ho, A ruthenium complex with superhigh light-harvesting capacity for dye-sensitized solar cells, Angew. Chem. Int. Ed. 45 (2006) 5822-5825.

[16] C.Y. Huang, Y.C. Hsu, J.G. Chen, V. Suryanarayanan, K.M. Lee, K.C. Ho, The effects of hydrothermal temperature and thickness of $\mathrm{TiO}_{2}$ film on the performance of a dye-sensitized solar cell, Sol. Energy Mater. Sol. Cells 90 (2006) 2391-2397.

[17] C. Longo, J. Freitas, M.A. De Paoli, Performance and stability of $\mathrm{TiO}_{2} /$ dye solar cells assembled with flexible electrodes and a polymer electrolyte, J. Photochem. Photobiol. A: Chem. 159 (2003) 33-39.

[18] B.C. O'Regan, J.R. Durran, Calculation of activation energies for transport and recombination in mesoporous $\mathrm{TiO}_{2} /$ dye/electrolyte films-taking into account surface charge shifts with temperature, J. Phys. Chem. B 110 (2006) 8544-8547.

[19] E. Hawlicka, R. Grabowski, W. Reimschuessel, Self-diffusion and conductance studies of acetonitrile. Water solutions of tetraethylammonium iodide, Ber. Bunsenges. Phys. Chem. 94 (1990) 158-162.

[20] M.K. Nazeeruddin, R.H. Baker, P. Liska, M. Grätzel, Investigation of sensitizer adsorption and the influence of protons on current and voltage of a dye-sensitized nanocrystalline $\mathrm{TiO}_{2}$ solar cell, J. Phys. Chem. B 107 (2003) 8981-8987.

[21] N. Kopidakis, E.A. Schiff, N.-G. Park, J. van de Lagemaat, A.J. Frank, Ambipolar diffusion of photocarriers in electrolyte-filled, nanoporous $\mathrm{TiO}_{2}$, J. Phys. Chem. B 104 (2000) 3930-3936.

[22] S.K. Deb, Dye-sensitized $\mathrm{TiO}_{2}$ thin-film solar cell research at the national renewable energy laboratory (NREL), Sol. Energy Mater. Sol. Cells 88 (2005) $1-10$.

[23] J. van de Lagemaat, A.J. Frank, Nonthermalized electron transport in dyesensitized nanocrystalline $\mathrm{TiO}_{2}$ films: transient photocurrent and randomwalk modeling studies, J. Phys. Chem. B 105 (2001) 11194-11205.

[24] K.D. Benkstein, N. Kopidakis, J. van de Lagemaat, A.J. Frank, Influence of the percolation network geometry on electron transport in dye-sensitized titanium dioxide solar cells, J. Phys. Chem. B 107 (2003) 7759-7767.

[25] G.T.K. Fey, J.G. Chen, V. Subramanian, T. Osaka, Preparation and electrochemical properties of $\mathrm{Zn}$-doped $\mathrm{LiNi}_{0.8} \mathrm{Co}_{0.2} \mathrm{O}_{2}$, J. Power Sources $112(2002)$ 384-394.

[26] J. van de Lagemaat, N.G. Park, A.J. Frank, Influence of electrical potential distribution, charge transport, and recombination on the photopotential and photocurrent conversion efficiency of dye-sensitized nanocrystalline $\mathrm{TiO}_{2}$ solar cells: a study by electrical impedance and optical modulation techniques, J. Phys. Chem. B 104 (2000) 2044-2052.

[27] W. Kubo, K. Murakoshi, T. Kitamura, S. Yoshida, M. Haruki, K. Hanabusa, $\mathrm{H}$. Shirai, Y. Wada, S. Yanagida, Quasi-solid-state dye-sensitized $\mathrm{TiO}_{2}$ solar cells: effective charge transport in mesoporous space filled with gel electrolytes containing iodide and iodine, J. Phys. Chem. B 105 (2001) 12809-12815.

[28] S. Yanagida, Recent research progress of dye-sensitized solar cells in Japan, C. R. Chim. 9 (2006) 597-604.

[29] Z. Huo, S. Dai, K. Wang, F. Kong, C. Zhang, X. Pan, X. Fang, Nanocomposite gel electrolyte with large enhanced charge transport properties of an $I_{3}^{-} / I^{-}$redox couple for quasi-solid-state dye-sensitized solar cells, Sol. Energy Mater. Sol. Cells 91 (2007) 1959-1965. 